\title{
A prospective, randomised comparison of single and three piece acrylic foldable intraocular lenses
}

\author{
R Nejima, K Miyata, M Honbou, T Tokunaga, T Tanabe, M Sato, T Oshika
}

Br J Ophthalmol 2004;88:746-749. doi: 10.1136/bjo.2003.037663

\begin{abstract}
Aims: To compare the postoperative performance of single and three piece acrylic foldable intraocular lenses (IOLs).

Methods: 20 patients underwent bilateral cataract surgery with a single piece SA30AL IOL in one eye and a three piece MA3OBA IOL in the other eye. The eyes were randomly assigned to either a single or three piece lens. The amount of IOL decentration and tilt, area of anterior capsule opening, and degree of posterior capsule opacification were measured using the Scheimpflug anterior segment analysis system (Nidek EAS-1000). Visual acuity and contrast sensitivity were examined. Measurements were performed by masked examiners before and 1 day, 1 week, 1, 3, 6, and 18 months after surgery.

Results: There were no significant differences between the two groups ( $p>0.05$, paired $t$ test) in the amount of $1 O L$ decentration, IOL tilt, area of anterior capsule opening, degree of posterior capsule opacification, best corrected visual acuity, and contrast sensitivity throughout the 18 month follow up period.

Conclusion: The single and three piece acrylic foldable IOLs are equally stable in the eye after surgery.
\end{abstract}

$\mathrm{T}$ he three piece hydrophobic acrylic foldable intraocular lens (IOL) (AcrySof, Alcon Laboratories, Inc) consists of a truncated hydrophobic optic and poly(methylmethacrylate) (PMMA) haptics. This lens has been widely accepted and has played a prominent part in cataract surgery since its introduction in $1994,{ }^{12}$ because of stable clinical results ${ }^{3-5}$ and a low incidence of posterior capsule opacification..$^{6-11}$ The optic geometry ${ }^{12-15}$ and strong adhesion to the posterior capsule $^{1617}$ are important factors contributing to successful clinical records.

The single piece AcrySof is a new version of the hydrophobic acrylic foldable IOL, with both the optic and haptics consisting of a foldable acrylic material. When compared with the three piece acrylic IOL (MA30BA), the single piece acrylic IOL (SA30AL) has similar overall length $(12.5 \mathrm{~mm})$ and optic diameter $(5.5 \mathrm{~mm})$. On the other hand, the optic edge of SA30AL $(0.43 \mathrm{~mm})$ is thicker than that of MA30BA $(0.14 \mathrm{~mm})$, and the haptics of MA30BA have 5 degree angulation, against a flat configuration of SA30AL. In addition, the haptic compression force is significantly lower with the single piece acrylic IOL. ${ }^{18}$ These different features are important parameters which may influence the outcomes of cataract surgery. To the best of our knowledge, however, there have been no published data on the clinical comparison of single and three piece acrylic foldable IOLs.

Despite the increasing popularity among surgeons, there is a paucity of information about the postoperative performance of single piece acrylic foldable IOLs. Clinically, there has been two non-comparative interventional case series describing the intraoperative and short term postoperative results after phacoemulsification and implantation of a single piece AcrySof lens. ${ }^{18} 19$ Experimentally, there have been two laboratory studies evaluating SA30AL IOL morphologically and clinicopathologically. ${ }^{14} 20$ We conducted a prospective, randomised, self controlled study to compare the long term clinical results of single and three piece acrylic foldable IOLs. Parameters tested included visual acuity, contrast sensitivity, amount of IOL decentration and tilt, area of anterior chamber opening (ACO), and degree of posterior capsule opacification (PCO).

\section{SUBJECTS AND METHODS}

Twenty patients with bilateral senile cataract (mean 71.1 (SD 4.8 ) years of age) scheduled to undergo phacoemulsification and IOL implantation were included in the study. There were seven men and 13 women. They were selected from consecutive cases among the clinic population who matched our inclusion criteria. None of the eyes had any history of previous ocular surgery. Eyes were not included if they had any ocular disease which can affect surgical outcomes. The research protocol had institutional review board approval, and written informed consent was obtained from each patient. The study adhered to the tenets of the Declaration of Helsinki.

One eye of the patient was assigned to a single piece SA30AL IOL, and the contralateral eye was allocated to a three piece MA30BA IOL. The assignment was randomly determined using an envelope method. All cataract operations, consisting of phacoemulsification and IOL implantation, were performed by one surgeon (KM). Except for IOL implantation, identical surgical methods were employed for each eye. Conjunctival peritomy was made at the upper limbus. Scleral pocket dissection was initiated approximately $1.0 \mathrm{~mm}$ posterior to the limbus. Continuous curvilinear capsulorhexis approximately $4.5 \mathrm{~mm}$ in diameter was created. After hydrodissection, phacoemulsification of the nucleus and cortical aspiration were performed. Then the anterior chamber was filled with a viscoelastic agent. The incision was enlarged to $3.5 \mathrm{~mm}$, and the SA30AL or MA30BA IOL was folded and implanted using forceps. It was confirmed by direct observation that all IOLs were implanted within the intact continuous capsulorhexis. Sutures were not used to close the corneoscleral incision. There were no intraoperative complications.

Best corrected visual acuity (BCVA), amount of IOL decentration and tilt, area of ACO, and degree of PCO were measured before and 1 day, 1 week, 1, 3, 6, and 18 months after surgery. Contrast sensitivity was assessed using CSV1000 (Vector Vision) at 18 months postoperatively. All measurements were performed by masked examiners who were unaware of the assignment of eyes.

The anterior segment analysis system (Nidek EAS-1000) was used to quantify the degree of IOL decentration and tilt, area of ACO, and degree of PCO. For decentration and tilt, 


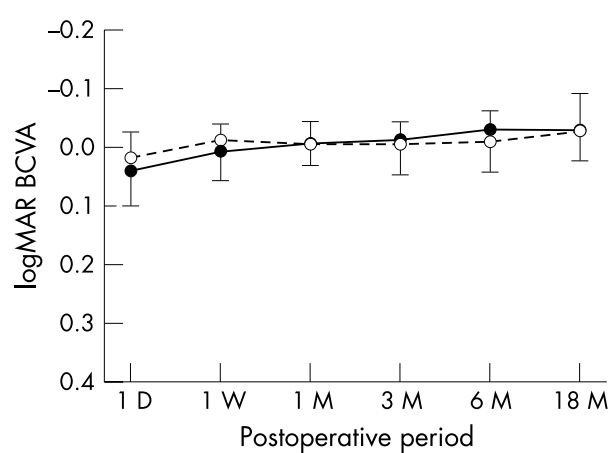

Figure 1 Logarithmic minimum angle of resolution (logMAR) for best corrected visual acuity (mean, SD). Closed circle = single piece SA3OAL; open circle $=$ three piece MA30BA. There was no significant difference between groups throughout the study period.

four Scheimpflug images of the IOL were taken after full mydriasis at slit angles of $0^{\circ}, 45^{\circ}, 90^{\circ}$, and $135^{\circ}$ with the CCD camera. The tilt angle of the IOL optic axis relative to the visual axis was quantified by the image analysis computer, and the length of decentration was indicated by the distance between the IOL optic vertex and the visual axis. ${ }^{21}{ }^{22}$ The area of ACO was measured on the retroillumination photograph taken with the EAS-1000. ${ }^{23}{ }^{24}$ The degree of PCO was also analysed using Scheimpflug slit images of four sections from $0^{\circ}$ to $135^{\circ}$. The mean density of the central $3 \mathrm{~mm}$ on the posterior capsular area was derived by densitometry and the scatter light density was expressed as the computer compatible tape (CCT) steps. ${ }^{25} 26$

Differences between the groups were assessed using the paired $t$ test. The test was two tailed and was applied at the $5 \%$ significance level.

\section{RESULTS}

The number of patients examined on each follow up occasion was 20 patients $(100 \%)$ at 1 day, 1 week, and 1 month, 15 patients $(75 \%)$ at 3 months, 12 patients $(60 \%)$ at 6 months, and 16 patients $(80 \%)$ at 18 months postoperatively.

The time course of changes in postoperative logarithmic minimum angle of resolution (logMAR) BCVA is shown in figure 1. Both groups attained satisfactory level of visual acuity, and there was no intergroup difference at any point.

The amount of IOL decentration (fig 2), IOL tilt (fig 3), area of ACO (fig 4), and degree of PCO (fig 5) were evaluated using the EAS-1000 Scheimpflug system. In all of these parameters, there were no significant differences between the groups throughout the 18 month follow up period.

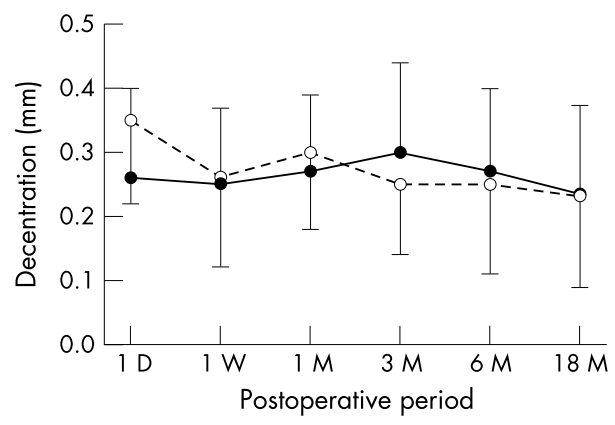

Figure 2 The amount of decentration of intraocular lenses (mean, SD). Closed circle $=$ single piece SA30AL; open circle $=$ three piece MA30BA. There was no significant difference between groups throughout the study period.

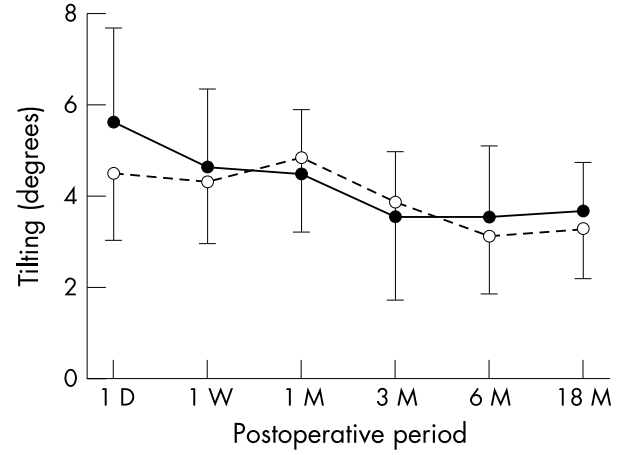

Figure 3 The degree of tilt of intraocular lenses (mean, SD). Closed circle $=$ single piece SA30AL; open circle $=$ three piece MA30BA. There was no significant difference between groups throughout the study period.

Contrast sensitivity assessed 18 months after surgery is shown in figure 6. At any spatial frequencies, no difference was observed between the groups.

\section{DISCUSSION}

In this study, we compared the postoperative data in 20 patients with bilateral cataract using the paired $t$ test. The difference in the amount of decentration between both eyes was 0.12 (SD 0.08 ) $\mathrm{mm}$ at 1 month postoperatively, indicating that a difference of $0.076 \mathrm{~mm}$ can be detected with a significance level of $5 \%(\alpha)$ and power of $90 \%(1-\beta)$ and a difference of $0.103 \mathrm{~mm}$ with a significance level of $1 \%$ and power of $95 \%$. For tilting 1 month after surgery, a difference of $0.997^{\circ}$ can be detected with a significance level of $5 \%$ and power of $90 \%$ and a difference of $1.353^{\circ}$ with a significance level of $1 \%$ and power of $95 \%$. A difference of $2.16 \mathrm{~mm}^{2}$ in the area of ACO can be detected with a significance level of $5 \%$ and power of $90 \%$ and a difference of $2.93 \mathrm{~mm}^{2}$ with a significance level of $1 \%$ and power of $95 \%$. As for the degree of PCO, a difference of 3.14 CCT can be detected with a significance level of $5 \%$ and power of $90 \%$ and a difference of 4.27 CCT with a significance level of $1 \%$ and power of $95 \%$. In addition to these statistical calculations, we found that both groups showed considerably similar time course of changes in all parameters throughout the follow up period. Thus, we believe that this study had sufficient power to detect significant differences, if any, after bilateral cataract surgery.

As shown in the results, the single piece SA30AL IOL and three piece MA30BA IOL showed a similar amount of decentration and tilt throughout the study period. In both groups, decentration and tilt did not progress up to

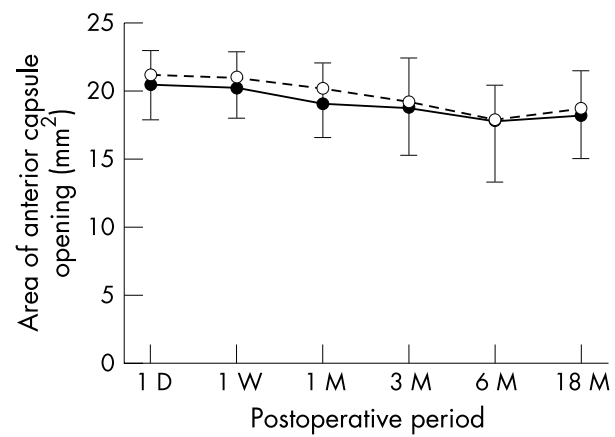

Figure 4 The area of anterior capsular opening (mean, SD). Closed circle $=$ single piece SA30AL; open circle $=$ three piece MA30BA. There was no significant difference between groups throughout the study period. 


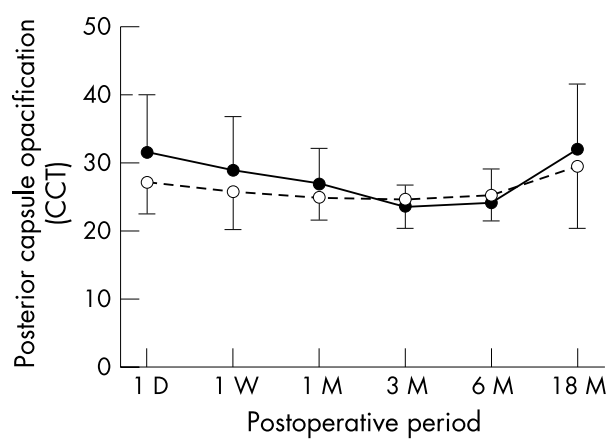

Figure 5 The extent of posterior capsule opacification (mean, SD).Values are expressed as computer compatible tape (CCT) steps. Closed circle = single piece SA30AL; open circle $=$ three piece MA3OBA There was no significant difference between groups throughout the study period.

18 months after surgery, and the extent of decentration and tilt was comparable with those of previous studies which also measured decentration and tilt using the EAS-1000 Scheimpflug analysis system for various IOLs, such as PMMA, ${ }^{22} 2728$ silicone, ${ }^{22} 2829$ acrylic foldable, ${ }^{22} 28-30$ and hydrogel lenses. ${ }^{30}$ In the current study, the degree of IOL tilt tended to improve up to 6 months after surgery (fig 3). This may be due to fibrosis of the lens capsule which might have contributed to securer fixation of the IOLs within the capsular bag.

The area of ACO did not differ significantly between the SA30AL and MA30BA lenses. The ACO area displayed slight tendency toward contraction up to 6 months after surgery, but the degree of contraction was not severe when compared with previous studies. ${ }^{23}{ }^{30} 31$ In a non-comparative case series, Caporossi et al reported that there was no case of major anterior capsule contraction during the 8 month follow up period after implantation of SA30AL IOL. ${ }^{18}$

There has been speculation that the wider and thicker loop of SA30AL IOL is disadvantageous in preventing PCO, because lens epithelial cells (LECs) may progress through the broad haptic-optic junction towards the centre of the posterior capsule. ${ }^{18} 32$ It has been reported that a discontinuous capsular bend or a rectangle created by the sharp, square optic edge of the IOL is important to inhibit LEC migration and to prevent PCO. ${ }^{33}{ }^{34}$ Adhesion of the anterior and posterior capsule is critical, and if this adhesion does not occur, bending is not formed in the posterior capsule and the mechanical barrier effect against LEC migration is diminished, as demonstrated by animal experiments. ${ }^{12}$ When IOLs that have large loop roots are used, such as single piece acrylic foldable IOL, adhesion of the anterior and posterior capsule would be less effectively created, and LECs may more readily migrate through the haptic root towards the centre of the posterior capsule. There has been a case report in which LEC migrated through the haptic root of SA30AL and PCO was formed 19 months after surgery. ${ }^{32}$ In the current study, there was no significant difference in the degree of PCO between the single piece SA30AL IOL and three piece MA30BA IOL. The degree of PCO, however, tended to increase in the SA30AL group after 6 months postoperatively (fig 5), though the difference was not statistically significant. Because only 32 eyes of 16 patients were followed up for 18 months after surgery, the current study alone cannot elucidate whether the incidence of PCO is different between these two types of acrylic foldable IOLs. This is the main weakness of our study, and thus a longer term study in a larger number of patients is needed to draw conclusions.

There has been a case report of acute haptic induced pigmentary glaucoma with a single piece acrylic foldable

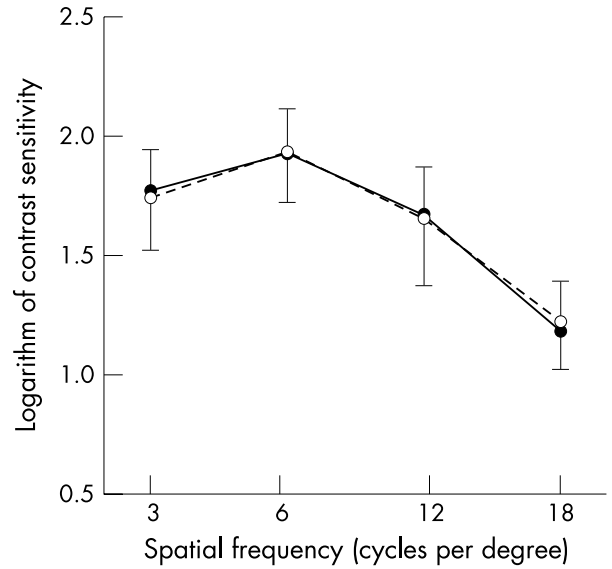

Figure 6 Logarithm of contrast sensitivity (mean, SD). Closed circle $=$ single piece SA30AL; open circle $=$ three piece MA30BA. There was no significant difference between groups throughout the study period.

IOL. ${ }^{35}$ It was postulated that one of the haptics slipped out of the capsular bag and came into contact with the pigmented iris and ciliary body. The manufacturer has not recommended implanting this IOL in the sulcus because of the zero angulation of the haptic-optic junction. The authors also stated that surgeons should avoid sulcus placement of the single piece acrylic foldable IOL because of the lens's potential to induce haptic related pigmentary glaucoma. ${ }^{35}$ As indicated by the current study, such a complication will not develop when the lens is implanted within the capsular bag, resulting in excellent centration and least amount of tilting.

In conclusion, the current 18 month prospective, randomised, self controlled study indicated that single and three piece acrylic foldable intraocular lenses were equally stable when implanted within the capsular bag. Both of these IOLs showed minimum amount of decentration, tilt, anterior capsule contraction, and posterior capsule opacification.

\section{Authors' affiliations}

R Nejima, K Miyata, M Honbou, T Tokunaga, T Tanabe, Miyata Eye Hospital, Miyazaki, Japan

M Sato, T Oshika, Department of Ophthalmology, Institute of Clinical Medicine, University of Tsukuba, Ibaraki, Japan

The authors have no commercial or proprietary interest in any of the companies, products, or methods described in this article.

Correspondence to: T Oshika, MD, Department of Ophthalmology, Institute of Clinical Medicine, University of Tsukuba, 1-1-1 Tennoudai, Tsukuba, Ibaraki, 305-8575 Japan; toshika@md.tsukuba.ac.jp

Accepted for publication 7 December 2003

\section{REFERENCES}

1 Leaming DV. Practice styles and preferences of ASCRS members-2002 survey. J Cataract Refract Surg 2003;29:1412-20.

2 Oshika T, Amano S, Araie M, et al. Current trends in cataract and refractive surgery in Japan: 1999 survey. Jpn J Ophthalmol 2001;45:383-7.

3 Oshika T, Suzuki Y, Kizaki $H$, et al. Two year clinical study of a soft acrylic intraocular lens. J Cataract Refract Surg 1996;22:104-9.

4 Mengual E, Garcia J, Elvira JC, et al. Clinical results of AcrySof intraocular lens implantation. J Cataract Refract Surg 1998;24:114-7.

5 Mullner-Eidenbock A, Amon M, Moser E, et al. Morphological and functional results of AcrySof intraocular lens implantation in children: prospective randomized study of age-related surgical management. J Cataract Refract Surg 2003;29:285-93.

6 Hollick EJ, Spalton DJ, Ursell PG, et al. The effect of polymethylmethacrylate, silicone, and polyacrylic intraocular lenses on posterior capsular opacification 3 years after cataract surgery. Ophthalmology 1999;106:49-54; discussion $54-5$. 
7 Oner FH, Gunenc U, Ferliel ST. Posterior capsule opacification after phacoemulsification: foldable acrylic versus poly(methyl methacrylate) intraocular lenses. J Cataract Refract Surg 2000;26:722-6.

8 Kucuksumer Y, Bayraktar S, Sahin S, et al. Posterior capsule opacification 3 years after implantation of an AcrySof and a MemoryLens in fellow eyes. J Cataract Refract Surg 2000;26:1176-82.

9 Sundelin K, Friberg-Riad Y, Ostberg A, et al. Posterior capsule opacification with AcrySof and poly(methyl methacrylate) intraocular lenses. Comparative study with a 3-year follow-up. J Cataract Refract Surg 2001; 27:1586-90.

10 Halpern MT, Covert D, Battista C, et al. Relationship of AcrySof acrylic and PhacoFlex silicone intraocular lenses to visual acuity and posterior capsule opacification. J Cataract Refract Surg 2002;28:662-9.

11 Casprini F, Tosi GM, Quercioli PP, et al. Comparison of AcrySof MA30BA and Sensar AR40 acrylic intraocular lenses. J Cataract Refract Surg 2002; 28: 1130-4.

12 Nishi O, Nishi K, Wickstrom K. Preventing lens epithelial cell migration using intraocular lenses with sharp rectangular edges. J Cataract Refract Surg 2000;26: 1543-9.

13 Nishi O, Nishi K, Akura J, et al. Effect of round-edged acrylic intraocular lenses on preventing posterior capsule opacification. J Cataract Refract Surg $2001 ; 27: 608-13$.

14 Vargas LG, Peng Q, Apple DJ, et al. Evaluation of 3 modern single-piece foldable intraocular lenses: clinicopathological study of posterior capsule opacification in a rabbit model. J Cataract Refract Surg 2002;28:1241-50.

15 Auffarth GU, Golescu A, Becker KA, et al. Quantification of posterior capsule opacification with round and sharp edge intraocular lenses. Ophthalmology 2003; 110:772-80.

16 Oshika T, Nagata T, Ishii Y. Adhesion of lens capsule to intraocular lenses of polymethylmethacrylate, silicone, and acrylic foldable materials: an experimental study. Br J Ophthalmol 1998;82:549-53.

17 Versura $\mathbf{P}$, Torreggiani A, Cellini $M$, et al. Adhesion mechanisms of human lens epithelial cells on 4 intraocular lens materials. J Cataract Refract Surg 1999:25:527-33.

18 Caporossi A, Casprini F, Tosi GM, et al. Preliminary results of cataract extraction with implantation of a single-piece AcrySof intraocular lens. J Cataract Refract Surg 2002;28:652-5.

19 Davison JA. Clinical performance of Alcon SA30AL and SA60AT single-piece acrylic intraocular lenses. J Cataract Refract Surg 2002;28:1112-23.

20 Escobar-Gomez M, Apple DJ, Vargas LG, et al. Scanning electron microscopic and histologic evaluation of the AcrySof SA30AL acrylic intraocular lens. Manufacturing quality and morphology in the capsular bag. J Cataract Refract Surg 2003;29:164-9.
21 Sasaki K, Sakamoto $Y$, Shibata $T$, et al. Measurement of postoperative intraocular lens tilting and decentration using Scheimpflug images. J Cataract Refract Surg 1989;15:454-7.

22 Hayashi K, Harada M, Hayashi $H$, et al. Decentration and tilt of polymethyl methacrylate, silicone, and acrylic soft intraocular lenses. Ophthalmology 1997; 104:793-8.

23 Kimura W, Yamanishi S, Kimura T, et al. Measuring the anterior capsule opening after cataract surgery to assess capsule shrinkage. J Cataract Refract Surg 1998;24:1235-8.

24 Hayashi K, Hayashi H, Matsuo K, et al. Anterior capsule contraction and intraocular lens dislocation after implant surgery in eyes with retinitis pigmentosa. Ophthalmology 1998;105:1239-43.

25 Hayashi K, Hayashi H, Nakao F, et al. In vivo quantitative measurement of posterior capsule opacification after extracapsular cataract surgery. Am J Ophthalmol 1998;125:837-43.

26 Tobari I, Iwaki Y, Miyake K. Effect of tranilast eyedrops in preventing posterior capsule opacification: preliminary study. J Cataract Refract Surg 1999;25:1394-9.

27 Hayashi K, Hayashi $\mathrm{H}$, Nakao F, et al. Comparison of decentration and tilt between one piece and three piece poly(methyl methacrylate) intraocular lenses. Br J Ophthalmol 1998;82:419-22.

$28 \mathrm{Kim}$ JS, Shyn KH. Biometry of 3 types of intraocular lenses using Scheimpflug photography. J Cataract Refract Surg 2001;27:533-6.

29 Jung CK, Chung SK, Baek NH. Decentration and tilt: silicone multifocal versus acrylic soft intraocular lenses. J Cataract Refract Surg 2000;26:582-5.

30 Hayashi K, Hayashi H, Nakao F, et al. Anterior capsule contraction and intraocular lens decentration and tilt after hydrogel lens implantation. Br J Ophthalmol 2001;85:1294-7.

31 Kato S, Oshika T, Numaga J, et al. Anterior capsular contraction after cataract surgery in eyes of diabetic patients. Br J Ophthalmol 2001;85:21-3.

32 Sugita S, Kato S, Oshika T. Migration of lens epithelial cells through haptic root of single-piece acrylic-foldable intraocular lens. Am J Ophthalmol (in press).

33 Nishi O, Nishi K, Sakanishi K. Inhibition of migration lens epithelial cells at the capsular bend created by the rectangular optic edge of a posterior chamber intraocular lens. Ophthalmic Surg Lasers 1998;29:587-94.

34 Nishi O, Nishi K. Preventing posterior capsule opacification by creating a discontinuous sharp bend in the capsule. J Cataract Refract Surg 1999;25:521-6.

35 Micheli T, Cheung LM, Sharma S, et al. Acute haptic-induced pigmentary glaucoma with an AcrySof intraocular lens. J Cataract Refract Surg 2002;28:1869-72. 